\title{
EDUCATIONAL HYPOGAMY AND SECOND BIRTHS IN HUNGARY
}

\section{Tamás Bartus}

\section{ABSTRACT}

Recently, a growing body of literature examined the implications of the reversal of the gender gap in education for family formation. This line of research mainly focuses on how educational hypogamy, that is, womens' partnership with men who have lower levels of education, shapes the characteristics of marriages and cohabiting unions in terms of income, gender equity and union stability. Less is known about the effect of educational hypogamy on second birth rates. In the present paper, we examine the effect of educational hypogamy on second birth rates in Hungary. Drawing on the economic theory of fertility and the bargaining perspective, we hypothesize that (1) educational hypogamy has a negative effect on second birth rates, and (2) the magnitude of that effect decreases with female education. The hypotheses are tested by using event history data from the first four waves of the Hungarian Generations and Gender Survey. The analyses are restricted to women born between 1951-1980 who were partnered at the time of first birth. We find that educational hypogamy decreases second birth rates among women born between 1971 and 1980. However, we do not find evidence that would support the second hypothesis. Nevertheless, second birth rates are relatively high in hypergamous partnerships among women with secondary education born between 1971 and 1980 .

Keywords: educational hypogamy, second birth rate, economic theory of fertility, marriage and union stability, hypergamous and homogamous partnerships 
Tamás Bartus

Professor and Director, Institute of Sociology and Social Policy, Corvinus University of Budapest, Hungary

E-mail: tamas.bartus@uni-corvinus.hu

\section{INTRODUCTION}

Educational expansion is often viewed as one of the causes of low fertility since the prolonged participation in education goes hand-in-hand with the postponement of family formation (Blossfeld and Huinink, 1991; Neels and de Wachter, 2010; Ni Bhrolcháin and Beaujouan, 2012; Beaujouan, Brzozowska and Zeman, 2016). Another mechanism which may explain the fertility effects of educational expansion relates to educational hypogamy, that is, partnerships in which She has more education than He does. Educational expansion is not a gender-neutral phenomenon: the share of women exceeds that of men among college graduates in several European countries, and the advantage of women seems to increase over time (Vincent-Lancrin, 2008; van Bavel, 2012). As the availabille pool of highly educated male partners becomes more and more limited, a growing share of educated women face the risk of "marrying down". Recently, several studies examined the implications of the reversal of gender gap in education as well as that of educational hypogamy (Esteve et al., 2016; Klesment and van Bavel, 2017; de Hauw, Grow and van Bavel, 2017). This line of research mainly focuses on how educational hypogamy shapes the characterstics of unions in terms of income, gender equity and union stability. Surprisingly, less effort was made to examine the the effect of hypogamy on fertility, in general, and on second birth rates in particular. Although research on the partner effect hypothesis (Kreyenfeld, 2002; Gerster et al., 2007; Klesment and Puur, 2010; Bartus et al., 2013) might provide some indirect evidence on the fertility effects of hypogamy, studies explicitly addressing the effect of educational hypogamy are rare (Nitsche et al., 2018).

The objective of the present paper is to fill in this gap by examining the effect of educational hypogamy on second birth rates in Hungary. The Hungarian case is interesting for two reasons. First, the number of women exceeds that of men among people aged 25-29 years old with a degree in tertiary education since about 1980, and ever since the difference is monotonically increasing (van Bavel, 2012, Figure 1). As we will show later, educational hypogamy is widespread among women with both secondary and tertiary education. Second, previous research found a U-shaped relationship between education and both fertility and second birth rates (Bartus et al., 2013; Husz, 2006; Bartus, 2017), which is rare in international 
comparison (Wood, Neels and Kil, 2014). This pattern cannot be explained simply with the help of the partner effect hypothesis because the U-shaped pattern persists even if the partner's education is taken into account (Bartus et al., 2013; Bartus, 2017). Educational hypogamy may turn a positive or negative educational gradient into a $U$-shaped one if hypogamy has a negative effect on second birth rates, this effect being the strongest (or the share of hypogamous partnerships is the highest) among women with secondary education.

Previous analyses of educational hypogamy relied on various theoretical ideas including New Home Economics, resource pooling, gender ideology and the bargaining perspective (van Bavel, 2012; Nitsche et al., 2018). The present paper assumes that education is a proxy for expected lifecycle earnings and makes use of the economic perspective to turn various ideas into empirically testable hypotheses. Economic analyses of fertility establish the link between education (and other socio-economic factors) and fertility using the concepts of income effect and price effect. We believe that the economic approach fits naturally within the Hungarian context in general, and Hungarian family policy in particular. The main objective of the Hungarian family support system especially since the 1980s is to provide generous cash benefits for women to compensate for foregone wage incomes during maternity and parental leave, and to provide additional financial support for families. During the last decades, more and more emphases were placed on cash transfers. However, investments into childcare arrangments and the promotion of flexible and part-time work opportunities were neglected. The availability of nurseries is very limited, and the vast majority of women exhaust the three-year period of paid leave (Blaskó, 2010). As a consequence, financial resources should play a vital role when making the decision on having a second child and how to combine family and work.

The paper is structured as follows. In the next section, we formulate two hypotheses on the fertility effect of educational hypogamy. Drawing on the economic analysis of fertility as well as the bargaining perspective, we hypothesize that parity progression rates should be higher in hypogamous partnerships, and that this effect decreases with female education. The first hypothesis is not a new one; it is suggested by previous work on educational hypogamy, and it can also be derived from the influential quality-quantity model of fertility. The second hypothesis however can be treated as an original one, even when some of the hypotheses formulated in Nitsche et al. (2018) suggest that the hypogamy effect is pronounced in some educational groups. Next, we describe the data and methods we use to examine the hypotheses. After presenting our results, we provide concluding remarks. 


\section{HYPOTHESES ON THE FERTILITY EFFECT OF EDUCATIONAL HYPOGAMY}

Van Bavel (2012) provides a detailed analysis of the causes and consequences of educational hypogamy. The ultimate macro-level cause is the expansion of higher education and the increase in the share of women in higher education. The decrease in the ratio of young men to young women among the college educated limits the opportunities of women to marry men with similar age and education to their own. Several alternatives are open to women to solve the problem: searching more intensively for educated men, even at the price of abandoning age homogamy; searching for educated partners in distant marriage markets; giving up those efforts and "marrying down"; and finally, refraining from marriage. There is evidence that educational hypogamy increases with the reversal of the gender gap in education (Esteve et al., 2016). Taken together, reversal of the gender gap in education is hypothesized to increase the share of hypogamous marriages.

The increase in hypogamous marriages have implications for union instability and dissolution. First, investment in and the creation of common values and lifestyles is more difficult for partners who have different levels of education (Esping-Andersen, 2009; van Bavel, 2012; Esteve et al., 2016). Educated people tend to prefer a managerial approach to the organization of leisure time and raising children, while people with lower educational levels tend to prefer a laissez-faire approach, meaning that spending leisure time should give the feeling of being free from self-constraints (Streib, 2015). Childraising for educated couples means that leisure time should be packed with organized cultural activities, including the consumption of high culture (Lareau, 2003). Hence, partners with different educational levels have conflicting views on how leisure time should be spent together with their (prospective) children.

Second, educational hypogamy may hinder women in achieving/realizing gender equity. Gender-role expectations are shaped by education: highly educated partners opt for gender-equity, while couples with low education are likely to stick to a traditional division of household tasks (Esping-Andersen, 2009). In educationally hypogamous partnerships, the contribution of women to household income may reach or even exceed the contribution of the partner. Becker's (1981) specialization argument suggests that in this case, women should specialize in the role of the breadwinner, and the role of housekeeping should be performed by the male partner. Achieving the reversal of traditional divison in household tasks is possible in theory since women have a good bargaining po- 
sition, given their high potential for better wage income. However, there is some evidence that highly educated women fail to enforce the gender-equal division of roles. For instance, Esping-Andersen (2009) finds that educational hypogamy increases, rather than decreases the amount of daily housework among highly educated Spanish women.' Relying on qualitative interviews with American families, Streib (2015) found that regardless of education, women are responsible for housework; the only difference that education makes is that educated women feel resentful and argue about the unequal divison of labor with their partners. In short, "marrying down" increases the likelihood of conflicts related to the division of household tasks. These conflicts may even contribute to the emergence of a low self-esteem, besides the fact that a partner with a lower level of education can have a negative effect on the perception of one's own status (Byrne and Barling, 2017).

If conflicts related to lifestyle and the division of housework are more pronounced in hypogamous partherships than in homogamous ones, it is likely that women marrying down tend to be less satisfied with their partnership and are more likely to break up the relationship. Being married to a person with a relatively low educational level, and the pessimistic expectations concerning the duration of the union immediately imply that the expected life-cycle income among hypogamous couples should be lower than among homogamous ones. $^{2}$

The implications of expected life-cycle income on fertility are elaborated within the economic theory of fertility. Jones, Schoonbroodt and Tertilt (2011) examine the influential quantity-quality model (Becker and Lewis, 1973), and show that the desired number of children is proportional to the ratio of the full lifecycle family income to lifecycle female wages. For analytical simplicity, we assume that women do all childcare work. This assumption is realistic in the Hungarian context, and there is also some evidence that division of domestic work becomes more traditional after the transition to parenthood in Germany as well (Nitsche and Grunow, 2016). We also assume that educational level is a proxy for lifecycle income.

\footnotetext{
'See Table 1.4, column "Wife's time". The effect of hypogamy among highly educated women is the sum of the main effect of hypogamy and the interaction term between higher education and hypogamy. This sum is about half an hour per day. ${ }^{2}$ This propositon does not assume that separated women will never repartner. Rather, the assumption is that educational hypogamy has no systematic effect on the expected hazard of repartnering and on the expected income of the new partner.
} 
Consider a partnership where both She and He have the same levels of education $E$. The desired number of children in this homogamous partnership is proportional to the ratio

$$
\frac{W_{E}^{M}+W_{E}^{F}}{W_{E}^{F}}
$$

where $W_{E}^{F}$ is her full lifecycle wage income, and $W_{E}^{M}$ is his full lifecycle wage income. ${ }^{3}$ The full lifecycle income is the (hypothetical) life-cycle income provided that He or She devotes all available time to work. Note that partnership instatiblity can be modeled in terms of full income. In the presence of the risk of divorce, the full income is a sum of elementary incomes in different partnership states, weighted by the relative duration of each of those states.

Consider now a partnership where a woman with level of education $E$ is partnered to a man with educational level $(E-1)$. The desired number of children in this hypogamous partnership should be proportional to the ratio

$$
\frac{W_{E-1}^{M}+W_{E}^{F}}{W_{E}^{F}}
$$

The effect of hypogamy on the demand of children is revealed by the difference between the ratios presented in (1) and (2), which is:

$$
\frac{W_{E}^{M}+W_{E-1}^{M}}{W_{E}^{F}}
$$

Given the positive educational gradient in both male and female wages, the difference in (3) is positive, that is, more children are desired in homogamous partnerships than in hypogamous ones. Hence, our first hypothesis reads as follows:

H1: Birth rates in educationally hypogamous partnerships are lower than those in educationally homogamous or hypergamous partnerships.

Hypothesis $\mathrm{H} 1$ does not explore all implications of economic theory. Equation (3) suggests that the magnitude of the negative fertility effect of educational hypogamy depends on a relative difference in male wages, which is defined as the absolute difference in wages between men with different levels of education, divided by female wages. Neither the absolute difference in male wages, nor the

${ }^{3}$ Throughout the paper, superscripts M and F identify males and females, respectively. 
magnitude of female wages are constant across educational groups. Consider a society where there are only three educational levels: Iow $(E=1)$, middle $(E=2)$ and high $(E=3)$. The hypogamy effect among women with a high level of education depends on the relative income difference

$$
\frac{W_{3}^{M}+W_{2}^{M}}{W_{3}^{M}}
$$

and the effect among women with a middle level of education is proportional to the relative income difference

$$
\frac{W_{2}^{M}+W_{1}^{M}}{W_{2}^{F}}
$$

These two relative income differences do not need to be the same. Hence, the magnitude of the hypogamy effect is likely to be conditional on her level of education. In short, there should be an interaction effect between educational hypogamy and her level of education.

In the literature, a specific interaction effect was suggested by Nitsche et al. (2018). Drawing upon the bargaining perspective of families (Blood and Wolf, 1960) and recent empirical research on the outsourcing of domestic work (de Ruijter, Treas and Cohen, 2005; Treas and de Ruijter, 2008; Schneider and Hastings, 2017), they argue that highly educated women have sufficient bargaining power to ease their involvement in domestic work. Although outsourcing domestic work decreases disposable income, it should have a positive effect on fertility intentions since outsourcing enables the combination of work and children better. ${ }^{4}$ Since outsourcing can be observed among highly educated women, it is reasonable to assume that educational hypogamy does not affect the bargaining power of highly educated women, but it does undermine the bargaining power of women with less education. The bargaining perspective leads us to the following hypothesis:

H2: The magnitude of the effect of hypogamy on second birth rates decreases with educational level.

\footnotetext{
${ }^{4} \mathrm{~A}$ formal argument runs as follows. Suppose that the couple decides to outsource 100t percent of the time that must be spent on raising children. One unit of time can be outsourced at price P. Thus, if t unit of domestic or childcare work is outsourced, full life-cycle family income decreases by Pt. However, outsourcing also implies that the time cost of raising children drops from $W$ to $W(1-t)$, where $W$ is her full wage income. Within the economic theory of fertility, fertility intentions are proportional to the ratio of the full income to the time cost. It can easily be shown that outsourcing increases this ratio provided that $P$ is smaller than the full income of the couple.
} 


\section{DATA AND METHODS}

We use the first four waves of the Hungarian Turning Points of the Life Course panel survey, collected in 2001, 2004, 2008 and 2012 by the the Hungarian Demographic Research Institute. The second and third waves correspond to the first and second waves of the Generations and Gender Survey (GGS), respectively. Using the four waves, a person-period dataset was created which contains time-varying information on births, partnerships and educational level.

In order to analyse the effect of educational hypogamy we need to construct educational histories for partners. This is a nontrivial task because respondents were not asked to provide details on their partners' educational histories. The only information available is the current partner's educational level at the time of the interview. To construct educational histories for partners, we matched the reported current educational levels to all person-months of the partnership spell, which included the time of the interviews.

Our method of constructing the partner's educational histories has two important implications. First, partners' educational levels are missing at an increasing rate as we move back in time. Note that partners' education remains unknown for partnership spells that started after an interview took place and ended before the subsequent interview. In the context of the present paper, the rate of missing information on educational pairing is substantially higher at the time of first conception than at the time of higher-order conceptions. This is one of the reasons why we chose to focus on second births in the present paper.

Second, our method of imputing partners' educational histories does not work for unstable partnerships. Consider a woman who marries somewhere between the first and second waves of the longitudinal survey. If the marriage survives and she participates also in the second wave, she can report her husband's education level and the reported educational level can be assigned to the full marriage history. But if her marriage breaks down before the second wave interview takes place, none of the information she provides on her current partnership can be used to reconstruct the education of the previous husband. Therefore, our procedure of measuring the partners' education introduces a bias: the event histories of women living in unstable partnerships are underrepresented in our analysis sample, which will be described below. The bias is substantial; our analysis sample includes only 55 out of the 186 spells which have ended in separation. The under-representation of unstable partnerships, together with the fact that partnership stability has an effect on birth rates, implies that our 
sample is selective, and our results can only be generalized to the population of mothers living in stable partnerships.

The analysis sample is restricted to women who (1) are born between 1951 and 1980 ( $N=4,911)$, (2) are mothers of one child and were partnered at the time of first birth $(N=1,661)$. After the exclusion of missing values, the analysis sample includes 1,657 women. The number of second conceptions is 1,188, and the (unweighted) number of person-months is 103,034. The average length of the risk period is around 62 months. The risk period comprises the period between 1970 and 2013.

In the event-history datafile used for analyses, the observation period starts immediately after the first child is delivered. The end of the observation period is marked by any of the following events: (1) second conception; (2) union dissolution; or (3) partner's death. Events of type (2) and (3) are treated as censored observations. Conceptions are identified by using the dates of second births; the dates of the second conceptions are defined as the birth date of the second child minus nine months.

The dependent variable is a dummy indentifying the conception leading to the second birth. The key explanatory variables are female education, partnership type identifying hypogamous, homogamous and hypergamous partnerships and educational pairing. Female education is a time-constrained variable measuring the level of education at the time of first birth. The variable has three categories: vocational education (lower secondary education), secondary education (upper secondary education completed with the Matura exam), and tertiary education (college or university degree). The partnership type variable classifies partnerships into hypogamous, homogamous and hypergamous partnerships in terms of the above educational categories at the time of first birth. The categories of the educational pairing variable are the combinations of female education and partnership type. It has eight categories since women with tertiary education cannot marry upwards.

We will use four age-related variables to capture duration dependence: age since first birth, age at first birth, the log of the age at first birth, and the ratio of age since first birth to age at first birth. This specification is motivated by the fact that observed birth rates and predicted birth hazards are typically bell-shaped functions of age. The bell-shaped pattern can be modeled using two log-age variables: log(49 - age) and log(age - 14) (Blossfeld and Huinink, 1991). The bellshaped pattern remains if we replace log(49-age) with the linear age variable (age - 15). When modeling second birth rates, the analysis time is age since first birth rather than absolute age. To model duration dependence in terms of age 
since first birth in a way which respects the bell-shaped distribution of birth rates, absolute age is replaced by the sum of age since first birth and age at first birth. The presence of the linear age variable justifies the use of age since first birth and age at first birth. The model specification is completed by approximating log(age - 14) with two nonlinear terms: log age at first birth and the ratio of age since first birth to age at first birth. ${ }^{5}$

We test our hypotheses using discrete-time event-history analysis, that is, by estimating logistic regression models of second conceptions using the person-period dataset. Admittedly, multinomial logistic regression models of the competing risks of second conceptions and separations would be more appropriate, since educational hypogamy is supposed to increase the risk of union dissolution as well. However, the competing-risk approach is not feasible with the data at hand because of the low number of separations. We made an attempt to estimate all models reported in this paper by using multinomial logistic regressions, but most of the estimates turned out to be numerically unreliable, and some of the models even failed to converge. This is the reason why the separation outcome is neglected in this paper and regression modeling makes use of the simple binary logistic regression.

The models are estimated by using the full sample, as well as for three birth cohorts (1951-1960, 1961-1970, 1971-1980) separately. The characteristics of these samples are described in Table A-1 in the Appendix. During estimation, we use a weight which reflects both the selectivity of panel continuation as well as differences in the relative frequencies of completed fertility and education between the sample and the population (Bartus, 2015). Because the person-months nested within persons cannot be considered as independent observations, we adjust the standard errors for clustering by estimating the Huber-Whyte sandwhich estimator, which is a standard feature of the statistical software, Stata.

Educational hypogamy might be an endogenous variable because "marrying down" is likely to be chosen by women who did not manage to find educated partners but do not wish to remain single (van Bavel, 2012). The unobserved factors shaping the position in the education-specific marriage squeeze might in fact overlap with unobserved factors influencing fertility intentions. A careful causal analysis should account for endogeneity, as well as for the selective nature of the sample. In the present paper, no attempt is made to use sophisticated statistical methods which have the potential to minimize these problems. The

${ }^{5}$ The idea is to use a first-order Taylor-series expansion to approximate $\log (a)=\log (b+c)$ as $\log (b)+c / b$, where a denotes age, $b$ denotes age at first birth, and $c$ denotes age since first birth. 
reason for this is that the dataset does not include a variable which would be a good candidate for the role of an excluded instrument. Because the findings reported here are reflecting the influcences of selection effects, statements about causal effects should be understood as statements about ceteris paribus relationships, and not as statements about treatment effects.

\section{RESULTS}

\section{Descriptives}

Table 1 shows the share of hypogamous and hypergamous partnerships across educational levels and cohorts. Educational hypogamy is the most pronounced among women with secondary education, especially among those who were born between 1961 and 1980. A similar pattern applies to college educated women, but the share of hypogamous partnerships is about 4 percentage points lower, compared to that of women with secondary education. Among women with vocational education, educational hypogamy is relatively rare and has been declining over time. Finally, note that the share of hypergamous partnerships dropped from 33 to $21 \%$ among women with secondary education. These findings suggest that the reversal of the gender gap in (higher) education affects not only college graduate women but also women who hold a secondary school certificate (Matura).

Table 1: The share of hypogamous and hypergamous partnerships across educational levels and cohorts, \%

\begin{tabular}{|c|c|c|c|}
\hline & Cohort 1951-1960 & Cohort 1961-1970 & Cohort 1971-1980 \\
\hline \multicolumn{4}{|c|}{ Hypogamous partnerships } \\
\hline vocational & 11.0 & 3.2 & 6.6 \\
\hline secondary & 29.3 & 37.1 & 35.8 \\
\hline tertiary & 25.4 & 31.7 & 31.4 \\
\hline N & 553 & 528 & 576 \\
\hline \multicolumn{4}{|c|}{ Hypergamous partnerships } \\
\hline vocational & 32.4 & 29.8 & 27.2 \\
\hline secondary & 32.7 & 22.8 & 20.6 \\
\hline N & 553 & 528 & 576 \\
\hline
\end{tabular}


Table 2 shows monthly second birth intensities per 1000 person-months. Second birth rate intensities range between 9 and 12 conceptions per 1000 person-months. The relationship between second birth rates and educational hypogamy varies across cohorts. In the youngest and the oldest birth cohorts there are no substantial differences in second birth rates across partnership statuses. In contrast, a clear pattern emerges in the 1961-1970 cohort: second birth rates increase as we move from hypogamous partnerhips to hypergamous ones. The relationship between second births and education follows a U-shaped pattern in the two oldest cohorts, while a positive educational gradient emerges in the youngest birth cohort. The relationship between second birth intensities and eduational pairings exhibit a U-shaped pattern. In the two oldest cohorts, the lowest birth rate characterizes the hypogamous partnerships of women with secondary education. In the youngest cohort however, hypergamous partnerships of women with vocational education exhibit the lowest rates of second births.

Table 2: Distribution of conceptions per 1000 person-months across explanatory variables by birth cohorts, \%

$\begin{array}{lccc} & \text { Cohort 1951-1960 } & \text { Cohort 1961-1970 } & \text { Cohort 1971-1980 } \\ \text { Overall mean } & 9.69 & 12.54 & 11.26 \\ \text { Partnership type } & & & \\ \text { hypogamy } & 9.74 & 10.31 & 10.21 \\ \text { homogamy } & 10.16 & 12.37 & 11.66 \\ \text { hypergamy } & 8.83 & 16.82 & 11.53 \\ \text { Education } & & & \\ \text { vocational } & 11.19 & 14.37 & 9.49 \\ \text { secondary } & 7.90 & 11.00 & 10.72 \\ \text { tertiary } & 14.18 & 12.82 & 17.26 \\ \text { Educational pairing } & & & \\ \text { She vocational - He lower } & 12.89 & 14.70 & 10.47 \\ \text { She vocational - He vocational } & 12.17 & 12.55 & 10.18 \\ \text { She vocational - He higher } & 9.40 & 20.57 & 7.74 \\ \text { She secondary - He lower } & 8.34 & 9.97 & 8.71 \\ \text { She secondary - He secondary } & 7.19 & 10.79 & 9.51 \\ \text { She secondary - He higher } & 8.42 & 13.56 & 18.22 \\ \text { She tertiary - He lower } & 14.12 & 10.21 & 13.94 \\ \text { She tertiary - He tertiary } & 14.21 & 14.53 & 19.53\end{array}$

Source: Waves 1-4 of the Turning Points of the Life Course panel survey (2001, 2004, 2008 and 2012), Hungarian Demographic Research Institute. 
Our second hypothesis implies that the magnitude of the hypogamy effect should increase with female education. We find this pattern in the 1961-1970 and the 1971-1980 birth cohorts. Among college graduates, second birth rates are lower in hypogamous partnerships. However, there is no similar pattern among women with secondary and vocational education. Finally, second birth rates are higher among women who have secondary education but their partner holds a college/university degree. The difference is substantial among women born in 1971-1980.

\section{Testing hypothesis $\mathrm{H} 1$}

Hypothesis $\mathrm{H1}$ claims that educational hypogamy has a negative effect on second births. To test the hypothesis, we estimate a discrete-time logistic regression of second births on hypogamy, educational level, four age-related variables, educational enrolment and birth cohort. Parameter estimates of the event history model are presented in Table 3. Within the full sample, the hypogamy dummy has a negative, statistically significant coefficient. The hypogamy coefficient is negative within all three cohorts, but it is significant in the youngest cohort only. These findings suggest that educational hypogamy and second birth rates are negatively related, but this relationship is driven by the behavior of the youngest cohort. The coefficent of the hypergamy dummy lacks statistical significance, thus we cannot draw any conclusions regarding the effect of educational hypergamy.

The coefficient on hypogamy in the 1971-1980 cohort (-0.2918) suggests that second birth intensities in hypogamous partnerships are about $100-100 \exp (-0.2918)=26 \%$ smaller compared to homoganous ones. We computed adjusted average predicted hazards by partnership type and we found that within the 1971-1980 cohort, monthly second birth intensities in hypogamous partnerships were about 9.3 births per 1000 persons. In homogamus and hypergamous partnerships, these rates are 12.2 and 12.9, respectively. The figures also show that the ratio of birth intensities in hypogamous partnerships to that in homogamous partnerships is about 3:4. A similar ratio should approximately characterize the ratios of the predicted probabilities of second births within any specific time interval. ${ }^{6}$ Hence, all

\footnotetext{
${ }^{6}$ The reason is that the probability of second births within a $T$ month period can be approximated as the sum of the monthly hazards within this period, and the ratio of the hazard in hypogamous partnerships to that in homogamous partnerships is approximately $\exp (b)$, where $b$ is the coefficient on hypogamy.
} 
things being equal the paritiy progression rate in hypogamous partnerships is about $75 \%$ of the rate which characterizes homogamous partnerships.

Table 3: Testing hypothesis H1: Parameter estimates of discrete-time logistic regressions of second births

\begin{tabular}{|c|c|c|c|c|}
\hline Variables & All cohorts & $\begin{array}{c}\text { Cohort } \\
1951-1960\end{array}$ & $\begin{array}{c}\text { Cohort } \\
1961-1970\end{array}$ & $\begin{array}{c}\text { Cohort } \\
1971-1980\end{array}$ \\
\hline \multicolumn{5}{|l|}{ Partnership type } \\
\hline \multirow[t]{2}{*}{ hypogamous } & $-0.1443^{*}$ & -0.0720 & -0.1565 & $-0.2918^{*}$ \\
\hline & $(1.999)$ & $(0.606)$ & $(1.295)$ & $(2.155)$ \\
\hline homogamous & 0 & 0 & 0 & 0 \\
\hline \multirow[t]{2}{*}{ hypergamous } & 0.0570 & 0.0097 & 0.1279 & 0.0389 \\
\hline & $(0.782)$ & $(0.084)$ & $(1.075)$ & $(0.263)$ \\
\hline \multicolumn{5}{|l|}{ Education } \\
\hline \multirow[t]{2}{*}{ vocational } & 0.0219 & 0.1774 & 0.0521 & $-0.3213^{*}$ \\
\hline & $(0.299)$ & (1.538) & $(0.417)$ & $(2.195)$ \\
\hline secondary & 0 & 0 & 0 & 0 \\
\hline \multirow[t]{2}{*}{ tertiary } & $0.5003^{* * *}$ & $0.5470^{* * *}$ & 0.1858 & $0.7845^{* * *}$ \\
\hline & $(6.568)$ & $(4.331)$ & $(1.508)$ & $(5.360)$ \\
\hline \multirow[t]{2}{*}{ Age at first birth - 15} & $-0.2213^{* * *}$ & $-0.2432^{* * *}$ & $-0.2811^{* * *}$ & -0.1243 \\
\hline & $(6.496)$ & $(3.951)$ & $(5.238)$ & (1.930) \\
\hline \multirow[t]{2}{*}{ Log(age at first birth - 14) } & $1.6141^{* * *}$ & $1.8396^{* * *}$ & $2.3654^{* * *}$ & 0.3444 \\
\hline & $(5.109)$ & $(3.380)$ & $(4.676)$ & $(0.550)$ \\
\hline \multirow[t]{2}{*}{ Age since first birth } & $-0.2963^{* * *}$ & $-0.3289^{* * *}$ & $-0.3034^{* * *}$ & $-0.1628^{* *}$ \\
\hline & $(12.177)$ & $(8.820)$ & $(6.799)$ & $(3.172)$ \\
\hline \multirow{2}{*}{$\begin{array}{l}\text { Age since first birth / } \\
\text { age at first birth }\end{array}$} & $0.8995^{* * *}$ & $1.0421^{* * *}$ & $0.9306^{* *}$ & 0.3406 \\
\hline & $(5.152)$ & $(3.967)$ & $(2.974)$ & $(0.936)$ \\
\hline \multirow[t]{2}{*}{ Birth cohort: 1951-1960 } & -0.0068 & - & - & - \\
\hline & $(0.100)$ & & & \\
\hline \multirow[t]{2}{*}{ Birth cohort: 1971-1980 } & $-0.2346^{* *}$ & - & - & - \\
\hline & $(3.222)$ & & & \\
\hline \multirow[t]{2}{*}{ Currently in school } & -0.0944 & -0.1404 & 0.2148 & -0.4046 \\
\hline & $(0.614)$ & $(0.622)$ & $(0.889)$ & $(1.207)$ \\
\hline \multirow[t]{2}{*}{ Constant } & $-5.3659^{* * *}$ & $-5.7001^{* * *}$ & $-6.4260^{* * *}$ & $-3.7115^{* * *}$ \\
\hline & $(12.464)$ & $(7.949)$ & $(9.287)$ & $(4.217)$ \\
\hline Number of persons & 1,657 & 553 & 528 & 576 \\
\hline Number of person-periods & 18,985 & 7,654 & 5,749 & 5,582 \\
\hline
\end{tabular}

Notes: Numbers in parentheses are $t$ statistics. Standard errors are adjusted for clustering using the Hubert-Whyte sandwhich estimator. ${ }^{*}=p<0.05,{ }^{* *}=p<0.01,{ }^{* * *}=p<0.001$.

Source: Waves 1-4 of the Turning Points of the Life Course panel survey (2001, 2004, 2008 and 2012), Hungarian Demographic Research Institute. 
Regarding the effect of female education, only the tertiary education variable has a significant coefficient in all cohorts. These coefficients are positive. This means that second birth rates among highly educated women are higher than among women with secondary education. Since the coefficients on the other education variables are not significant, we cannot decide whether the educational gradient in second births is positive or U-shaped.

We repeated the analyses with a specification which also includes interactions among the educational level dummies and the age variables. The inclusion of interaction terms relaxes the assumption that the effect of education on second birth schedules consist in shifting a common distribution or schedule towards older or younger age intervals. In the presence of ageeducation interaction terms, different educational groups can have different distributions characterizing the second birth schedules. Results are not reported here because the qualitative conclusions are the same as before: educational hypogamy is negatively related to second birth rates, but this evidence is significant only in the youngest birth cohort. This relationship is strong enough to generate a statistically significant negative relationship within the full sample.

\section{Testing hypothesis $\mathrm{H} 2$}

Hypothesis $\mathrm{H} 2$ claims that the magnitude of the hypogamy effect decreases with female education. To test the hypothesis, we modify the previously estimated specification and we replace the partnership status and female education variables with the educational pairing variables. The estimates are presented in Table 4. The reference category is the partnership of men and women both with secondary education. The category indicating educational hypogamy among women with secondary education has a negative but statistically insignificant coefficient. In contrast, the coefficient on the pairing "She secondary - He higher" is positive and statistically significant in the full sample, as well as in the 19711980 birth cohort. These estimates suggest that the hypothesized hypogamy effect arises only if we compare hypogamous partnersips to non-hypogamous ones. But this effect is due to the positive effect of educational hypergamy in the 1971-1980 birth cohort. 
Table 4: Testing hypothesis H2: Parameter estimates of discrete-time logistic regressions of second births

\begin{tabular}{|c|c|c|c|c|}
\hline Variables & All cohorts & $\begin{array}{c}\text { Cohort } \\
1951-1960\end{array}$ & $\begin{array}{c}\text { Cohort } \\
1961-1970\end{array}$ & $\begin{array}{c}\text { Cohort } \\
1971-1980\end{array}$ \\
\hline \multicolumn{5}{|l|}{ Educational pairing } \\
\hline \multirow{2}{*}{ She vocational - He lower } & 0.0776 & 0.2589 & 0.0897 & -0.3082 \\
\hline & $(0.411)$ & $(0.837)$ & $(0.252)$ & $(0.916)$ \\
\hline \multirow[t]{2}{*}{ She vocational - He vocational } & 0.0562 & 0.2267 & -0.0158 & -0.0871 \\
\hline & $(0.561)$ & $(1.424)$ & $(0.090)$ & $(0.459)$ \\
\hline \multirow[t]{2}{*}{ She vocational - He higher } & 0.0699 & 0.1753 & 0.2327 & -0.3981 \\
\hline & $(0.600)$ & $(0.914)$ & $(1.295)$ & $(1.669)$ \\
\hline \multirow[t]{2}{*}{ She secondary - He lower } & -0.1043 & -0.0214 & -0.1694 & -0.1424 \\
\hline & $(1.047)$ & $(0.137)$ & $(0.997)$ & $(0.701)$ \\
\hline She secondary - He secondary & 0 & 0 & 0 & 0 \\
\hline \multirow{2}{*}{ She secondary - He higher } & $0.2144^{*}$ & 0.1811 & 0.0701 & $0.6006^{*}$ \\
\hline & $(1.960)$ & $(1.135)$ & $(0.367)$ & $(2.534)$ \\
\hline \multirow[t]{2}{*}{ She tertiary - He lower } & $0.3692^{* *}$ & $0.5350^{*}$ & -0.0220 & $0.6094^{*}$ \\
\hline & $(2.725)$ & $(2.269)$ & $(0.100)$ & $(2.354)$ \\
\hline \multirow[t]{2}{*}{ She tertiary - He tertiary } & $0.6190^{* * *}$ & $0.7417^{* * *}$ & 0.2656 & $0.9504^{* * *}$ \\
\hline & $(6.031)$ & $(4.591)$ & $(1.533)$ & $(4.456)$ \\
\hline \multirow[t]{2}{*}{ Age at first birth - 15} & $-0.2329^{* * *}$ & $-0.2630^{* * *}$ & $-0.2822^{* * *}$ & -0.1285 \\
\hline & $(6.766)$ & $(4.076)$ & $(5.237)$ & $(1.959)$ \\
\hline \multirow[t]{2}{*}{ Log(age at first birth - 14) } & $1.6770^{* * *}$ & $1.9344^{* * *}$ & $2.3384^{* * *}$ & 0.3831 \\
\hline & $(5.299)$ & $(3.433)$ & $(4.580)$ & $(0.600)$ \\
\hline \multirow[t]{2}{*}{ Age since first birth } & $-0.2927^{* * *}$ & $-0.3229^{* * *}$ & $-0.3025^{* * *}$ & $-0.1578^{* *}$ \\
\hline & $(12.268)$ & $(9.012)$ & $(6.860)$ & $(3.069)$ \\
\hline \multirow{2}{*}{$\begin{array}{l}\text { Age since first child / } \\
\text { age at first birth }\end{array}$} & $0.8908^{* * *}$ & $1.0275^{* * *}$ & $0.9330^{* *}$ & 0.3442 \\
\hline & $(5.193)$ & $(4.073)$ & $(3.032)$ & $(0.947)$ \\
\hline \multirow[t]{2}{*}{ Birth cohort: 1951-1960 } & -0.0082 & - & - & - \\
\hline & $(0.120)$ & & & \\
\hline \multirow[t]{2}{*}{ Birth cohort: 1971-1980 } & $-0.2307^{* *}$ & - & - & - \\
\hline & $(3.160)$ & & & \\
\hline \multirow[t]{2}{*}{ Currently in school } & -0.1020 & -0.1105 & 0.2177 & -0.5766 \\
\hline & $(0.655)$ & $(0.479)$ & $(0.902)$ & $(1.545)$ \\
\hline \multirow[t]{2}{*}{ Constant } & $-5.4532^{* * *}$ & $-5.8141^{* * *}$ & $-6.3509^{* * *}$ & $-3.9137^{* * *}$ \\
\hline & $(12.570)$ & $(7.813)$ & $(8.924)$ & $(4.330)$ \\
\hline Number of persons & 1,657 & 553 & 528 & 576 \\
\hline Number of person-periods & 18,988 & 7,654 & 5,749 & 5,585 \\
\hline
\end{tabular}

Notes: Numbers in parentheses are $t$ statistics. Standard errors are adjusted for clustering using the Hubert-Whyte sandwhich estimator. ${ }^{*}=p<0.05,{ }^{* *}=p<0.01,{ }^{* * *}=p<0.001$.

Source: Waves 1-4 of the Turning Points of the Life Course panel survey (2001, 2004, 2008 and 2012), Hungarian Demographic Research Institute. 
As we move to women with tertiary education, we can see that the coefficients on both "She tertiary - He lower" and "She tertiary - He tertiary" are positive. The coefficients are significant in the youngest and the olderst cohorts, as well as in the full sample. Furthermore, the coefficient on "She tertiary - He lower" is smaller than that on "She tertiary - He tertiary", which seems to be consistent with Hypothesis H2. However, the coefficients in themselves do not help us to assess Hypothesis H2, which states that the hypogamy effect is smaller among women with secondary education than that among college graduates. Formally, the hypothesis implies the inequality

$$
\left(b_{T T}-b_{T L}\right)-\left(b_{S S}-b_{S L}\right)>0
$$

where the bs are the estimated regression coefficients, and the subscripts $T T, T L$, SS and SL refer to the respective educational pairings "She tertiary - He tertiary", "She tertiary - He lower", "She secondary - He secondary", and "She secondary - He lower". In our model, "She secondary - He secondary" is the reference category. Hence, $b_{S S}=0$ and the inequality becomes

$$
\left(b_{T T}-b_{T L}\right)+b_{S L}>0
$$

We therefore calculated the quantitites $\left(b_{T T}-b_{T L}\right)$ and $b_{S L}$, as well as the difference between those quantitites. The results are presented in Table 5. The hypogamy effect among women with higher education is negative but lacking statistical significance in all cohorts. Similarly, we do not find a statistically significant hypogamy effect among women with secondary education. Finally, the difference of those effects lack statistical significance in the full sample, as well as in all birth cohorts. Hence, the evidence at hand is not strong enough to support (or reject) our hypothesis regarding the hypogamy-education interaction. However, as we noted earlier, we could observe a statistically significant hypogamy effect among women with secondary education if we would compare hypogamous partnerships to non-hypogamous ones. An effect that is driven by the fact that educational hypergamy has a positive effect among women with secondary education.

Comparisons of the predicted second birth intensities, summarized in Table 6 , lead to the same conclusion. The second birth intensities are by far the highest among highly educated homogamous couples. In the 1971-1980 cohort, the predicted monthly birth intensity is $26.8 \pm 7.4$ birth per 1000 women. If a college graduated woman marries downwards, the predicted birth intensitiy drops to about 20 \pm 7.6 births per 1000 women. Thus, the confidence intervals overlap and we cannot be sure that educational hypogamy decreases seond birth intensities among 
women with tertiary education. If we move to women with secondary education, hypergamous couples stand out with a predicted rate of $19.5 \pm 6.7$, and the birth intensities of homogamous and hypogamous couples are very close to each other.

Table 5: Estimated hypogamy effects among women with secondary and tertiary education in Hungary

\begin{tabular}{lcccc}
\hline Age and education & All cohorts & Cohort & Cohort & Cohort \\
tertiary & $-0.2497-1960$ & -0.2066 & -0.2877 & -0.3410 \\
& $(1.9135)$ & $(0.8959)$ & $(1.3543)$ & $(1.4238)$ \\
secondary & -0.1043 & -0.0214 & -0.1694 & -0.1424 \\
& $(1.0479)$ & $(0.1377)$ & $(0.9971)$ & $(0.7015)$ \\
difference & -0.1454 & -0.1852 & -0.1183 & -0.1986 \\
& $(0.8884)$ & $(0.6664)$ & $(0.4365)$ & $(0.6315)$
\end{tabular}

Notes: Linear combinations of coefficients from Table 4. Numbers in parentheses are t statistics.

Source: Waves 1-4 of the Turning Points of the Life Course pane/ survey (2001, 2004, 2008 and 2012), Hungarian Demographic Research Institute.

Table 6: Predicted second birth hazards

\begin{tabular}{lcccc}
\hline Educational pairing & All cohorts & $\begin{array}{c}\text { Cohort } \\
\text { C51-1960 }\end{array}$ & $\begin{array}{c}\text { Cohort } \\
1961-1970\end{array}$ & $\begin{array}{c}\text { Cohort } \\
1971-1980\end{array}$ \\
\hline She vocational - He lower & 11.048 & 12.017 & 16.079 & 8.798 \\
& $(3.666)$ & $(6.234)$ & $(9.206)$ & $(4.644)$ \\
She vocational - He vocational & 10.341 & 10.382 & 12.382 & 9.580 \\
& $(1.627)$ & $(2.864)$ & $(3.313)$ & $(2.255)$ \\
She vocational - He higher & 10.544 & 10.035 & 15.847 & 7.316 \\
& $(2.013)$ & $(3.277)$ & $(4.428)$ & $(2.592)$ \\
She secondary - He lower & 8.822 & 8.120 & 10.571 & 9.146 \\
& $(1.351)$ & $(2.187)$ & $(2.546)$ & $(2.437)$ \\
She secondary - He secondary & 9.791 & 8.288 & 12.605 & 10.600 \\
& $(1.584)$ & $(2.217)$ & $(3.475)$ & $(3.066)$ \\
She secondary - He higher & 12.117 & 9.904 & 13.591 & 19.480 \\
& $(2.128)$ & $(2.649)$ & $(4.038)$ & $(6.678)$ \\
She tertiary - He lower & 14.261 & 14.731 & 12.689 & 19.962 \\
She tertiary - He tertiary & $(3.276)$ & $(5.964)$ & $(4.537)$ & $(7.620)$ \\
& 17.929 & 17.037 & 16.265 & 26.778 \\
& $(2.771)$ & $(4.287)$ & $(4.193)$ & $(7.418)$
\end{tabular}

Notes: Average adjusted predictions calculated from the coefficients reported in Table 4. Numbers in parentheses are $95 \%$ confidence inervals around the predictions. When calculating the predictions, educational pairing is changed to the requested category, but all other variables are left at ther actual level.

Source: Waves 1-4 of the Turning Points of the Life Course pane/ survey (2001, 2004, 2008 and 2012), Hungarian Demographic Research Institute. 


\section{DISCUSSION}

The present paper examines the effect of educational hypogamy on second birth rates in Hungary. Our empirical study is motivated by two hypotheses. Previous work on educational hypogamy argued that "partnering down" has a negative effect on birth rates. This argument easily fits into the economic theory of fertility. Our first hypothesis is that hypogamy has a negative effect on second birth rates. However, this hypothesis does not exploit all implications of the economic theory. Drawing on the bargaining perspective, we also hypothesize that the magnitude of the negative effect of hypogamy decreases with levels of education.

The hypotheses are examined by using the first four waves of the Hungarian GGS survey. We found that among women with the same educational levels, age and educational enrolment, hypogamy is indeed associated with lower second birth intensities within the 1971-1980 cohort. In contrast, we do not find convincing evidence regarding the hypothesis claiming that the magnitude of the hypogamy effect would decrease with education. The evidence at hand suggests that among women with secondary education, there is a statistically significant difference between hypergamous and homogamous partnerships, but no statistically significant difference between hypogamous and homogamous ones. These differences imply however that second birth intensities are lower in hypogamous couples than in non-hypogamous ones.

Our hypotheses involve four effects: Hypothesis $\mathrm{H} 1$ is about an overall hypogamy effect, while Hypothesis $\mathrm{H} 2$ considers two conditional effects and makes a claim about the difference of those effects. All of those four effects were examined in three birth cohorts. Out of the twelve cohort-specific effects, only one turned out to be statistically significant: the overall effect of educational hypogamy in the youngest birth cohort. An obvious explanation of this failure is sample size: dependening on birth cohort, the number of persons ranges between 553 and 576. Another explanation may be the increase in the true effect size over time. The economic perspective suggests that the magnitude of the hypogamy effect is proportional to the loss in life-cyle income which is caused by marrying downwards. The true effect is likely to be larger in the 1971-1980 cohort because members of this cohort were exposed to second births during the second half of the 1990s, when wage inequalities dramatically increased (see the Appendix in Bartus et al., 2013). In contrast, wage inequlities were moderate before 1990, the historical period where most of the women born between 1951-1960 delivered their second child. The nonsignificant findings in the older birth cohorts may 
reflect the fact that the wage loss from educational hypogamy was relatively moderate in socialist Hungary. Finally, note that our sample is highly selective: as elaborated in the Data and Methods section, the sample excludes unstable partnerships. Hence, unobserved factors which contribute to partnership stability should be overrepresented in the sample of the analysis.

When examining the implications of educational hypogamy for second birth rates, we relied on findings on the diffeences between white-collar and blue-collar class cultures and class-based conflicts within families (Lareau, 2003; Streib, 2015). If the hypogamy effects observed in the present paper are results of conflicts of this kind, then we should assume that the culture of people with secondary education is more similar to that of the college graduates than to the culture of people with secondary education. Under this assumption, the level of cultural conflict arising from "marrying down" should be the highest among women with secondary education. Hence, the extent of the negative hypogamy effect on fertility would be larger for women with secondary education than that of women with tertiary education. Unfortunately, we were not able to identify independent data sources or stylized facts which would justify this assumption regarding the relationship between education and class cultures. This is the reason why we do not formulate an alternative hypothesis on the hypogamy-education interaction. Further research should examine the extent to which "marrying down" causes family conflicts among women with different levels of education.

Previous research documented a U-shaped relationship between female education and second birth rates. (Husz, 2006; Spéder, 2006; Bartus et al., 2013; Bartus, 2017). In an international comparison, this is a rather unique pattern since the educational gradient in second births is either negative or positive in most of the other European countries (Kreyenfeld, 2002; Gerster et al., 2007; Beaujouan and Solaz, 2008; Klesment and Puur, 2010; Mureșan and Hoem, 2010; Billingsley, 2011; Wood, Neels and Kil, 2014). The results of the present paper suggest that the $\mathrm{U}$-shaped pattern is a real phenomenon: if the relative education of the partner is kept at a constant level, college educated women have higher second birth intensitives than that of women with secondary education. As a consequence, further research is needed to understand more comprehensively the U-shaped educational gradient in second birth rates. 


\section{REFERENCES}

Bartus, T. (2015). Lemorzsolódás és súlyozás az Életünk fordulópontjai panelfelvételben. [Attrition in and weights for the Hungarian Generations and Gender Survey] Demográfia, 58(4), pp. 287-308.

Bartus, T. (2017). Az iskolai végzettség és a második gyermekvállalás. Bizonyítékok az Életünk fordulópontjai adatbázisból [Education and second births. Evidence from the Hungarian Generations and Gender Survey]. Demográfia, 60(2-3), pp. 149-172.

Bartus, T., Murinkó, L., Szalma, I. and Szél, B. (2013). The effect of education on second births in Hungary: A test of the time-squeeze, self-selection and partner-effect hypotheses. Demographic Research, 28(1), pp. 1-32.

Beaujouan, E., Brzozowska, Z. and Zeman, K. (2016). The limited effect of increasing educational attainment on childlessness trends in twentieth-century Europe, women born 1916-65. Population Studies, 70(3), pp. 275-291.

Becker, G. (1981). A treatise on the family. $2^{\text {nd }}$ ed. Cambridge, MA: Harvard University Press. Becker, G. and Lewis, H. G. (1973). On the interaction between the quantity and quality of children. Journal of Political Economy, 81(2), pp. S279-S288.

Billingsley, S. (2011). Economic crisis és recovery: Changes in second birth rates within occupational classes and educational groups. Demographic Research, 24(16), pp. 375-406.

Blaskó, Zs. (2010). Childcare and employment. In: J. Monostori, P. Őri, E. S. Molnár and Zs. Spéder, eds., Demographic portrait of Hungary 2009: Report on the conditions of the Hungarian population. Budapest: HCSO Demographic Research Institute, pp. 41-50.

Blood, R. O. and Wolf, D. M. (1960). Husbands and wives: The dynamics of married living. New York, NY: Free Press.

Blossfeld, H-P. and Huinink, J. (1991). Human capital investment or norms of role transition? How women's schooling and career affect the process of family formation. American Journal of Sociology, 97(1), pp. 143-168.

Byrne, A. and Barling, J. (2017). When she brings home the job status: Wives' job status, status leakage, and marital instability. Organization Science, 28(2), pp. 177-192.

de Hauw, Y., Grow, A. and van Bavel, J. (2017). The reversed gender gap in education and assortative mating in Europe. European Journal of Population, 33(4), pp. 445-474.

de Ruijter, E., Treas, J. K. and Cohen, P. N. (2005). Outsourcing the gender factory: Living arrangements and service expenditures on female and male tasks. Social Forces, 84(1), pp. 305-322.

Esping-Andersen, G. (2009). The incomplete revolution: Adapting to women's new roles. Cambridge: Polity Press.

Esteve, A., Schwartz, C. R., van Bavel, J., Permanyer, I., Klesment, M. and García-Román, J. (2016). The end of hypergamy: Global trends and implications. Population and Development Review, 42(4), pp. 615-625.

Gerster, M., Keiding, N., Knudsen, L. B. and Strandberg-Larsen, K. (2007). Education and second birth rates in Denmark 1981-1994. Demographic Research, 17(8), pp. 181-210.

Husz, I. (2006). Iskolázottság és a gyermekvallalas időzítése. [Education and the timing of childbearing] Demográfia, 49(1), pp. 46-67. 
Jones, L. E., Schoonbroodt, A. and Tertilt, M. (2011). Fertility theories: Can they explain the negative fertility-income relationship? In: J. B. Shoven, ed., Demography and the economy. Chicago: University of Chicago Press, pp. 43-100.

Klesment, M. and Puur, A. (2010). Effects of education on second births before and after societal transition: Evidence from the Estonian GGS. Demographic Research, 22(28), pp. 891-932.

Klesment, M. and van Bavel, J. (2017). The reversal of the gender gap in education, motherhood, and women as main earners in Europe. European Sociological Review, 33(3), pp. 465-481.

Kreyenfeld, M. (2002). Time-squeeze, partner effect or self-selection? An investigation into the positive effect of women's education on second birth risks in West Germany. Demographic Research, 7(2), pp. 15-48.

Lareau, A. (2003). Unequal childhoods: Class, race, and family life. Berkeley: University of California Press.

Mureșan, C. and Hoem, J. (2010). The negative educational gradients in Romanian fertility. Demographic Research, 22(4), pp. 95-114.

Neels, K. and de Wachter, D. (2010). Postponement and recuperation of Belgian fertility: How are they related to rising female educational attainment? Vienna Yearbook of Population Research, 8, pp. 77-106.

Ní Bhrolcháin, M. N. and Beaujouan, E. (2012). Fertility postponement is largely due to rising educational enrolment. Population Studies, 66(3), pp. 311-327.

Nitsche, N. and Grunow, D. (2016). Housework over the course of relationships: Gender ideology, resources, and the division of housework from a growth curve perspective. Advances in Life Course Research, 29, pp. 80-94.

Nitsche, N., Matysiak, A., van Bavel, J. and Vignoli, D. (2018). Partner's educational pairings and fertility across Europe. Demography, 55(4), pp. 1195-1232.

Schneider, D. and Hastings, O. P. (2017). Income inequality and household labor. Social Forces, 96(2), pp. 481-506.

Spéder, Zs. (2006). Rudiments of recent fertility decline in Hungary: Postponement, educational differences, and outcomes of changing partnership forms. Demographic Research, 15(8), pp. 253-288.

Streib, J. (2015). The power of the past. Understanding cross-class marriages. Oxford: Oxford University Press.

Treas, J. and de Ruijter, E. (2008). Earnings and expenditures on household services in married and cohabiting unions. Journal of Marriage and Family, 70(3), pp. 796-805.

van Bavel, J. (2012). The reversal of gender inequality in education, union formation and fertility in Europe. Vienna Yearbook of Population Research, 10, pp. 127-154.

Vincent-Lancrin, S. (2008). The reversal of gender inequalities in higher education: An on-going trend. In: OECD, Higher Education to 2030, Volume 1, Demography. Paris: OECD Publishing.

Wood, J., Neels, K. and Kil, T. (2014). The educational gradient of childlessness and cohort parity progression in 14 low fertility countries. Demographic Research, 31(46), pp. 1365-1416. 


\section{APPENDIX}

Table A-1: Descriptive statistics in the estimation sample

Panel A: Dataset of person-months

\begin{tabular}{|c|c|c|c|}
\hline Variables & $\begin{array}{c}\text { Cohort } \\
1951-1960 \\
(N=7,654)\end{array}$ & $\begin{array}{c}\text { Cohort } \\
1961-1970 \\
(N=5,749)\end{array}$ & $\begin{array}{c}\text { Cohort } \\
1971-1980 \\
(N=5,585)\end{array}$ \\
\hline Second conception / 1000 person-month & 9.69 & 12.54 & 11.26 \\
\hline \multicolumn{4}{|l|}{ Partnership type } \\
\hline hypogamous & 23.99 & 26.71 & 26.05 \\
\hline homogamous & 48.13 & 57.04 & 54.20 \\
\hline hypergamous & 27.87 & 16.23 & 19.73 \\
\hline \multicolumn{4}{|l|}{ Education } \\
\hline vocational & 30.41 & 35.19 & 43.44 \\
\hline secondary & 56.99 & 45.32 & 40.20 \\
\hline tertiary & 12.59 & 19.48 & 16.35 \\
\hline \multicolumn{4}{|l|}{ Educational pairing } \\
\hline She vocational - He lower & 2.73 & 1.54 & 2.51 \\
\hline She vocational - He vocational & 16.18 & 26.09 & 28.33 \\
\hline She vocational - He higher & 11.48 & 7.55 & 12.59 \\
\hline She secondary - He lower & 17.60 & 17.47 & 16.90 \\
\hline She secondary - He secondary & 23.00 & 19.16 & 16.14 \\
\hline She secondary - He higher & 16.38 & 8.68 & 7.14 \\
\hline She tertiary - He lower & 3.65 & 7.70 & 6.63 \\
\hline She tertiary - He tertiary & 8.93 & 11.78 & 9.72 \\
\hline Age at first birth - 15 & 9.07 & 8.50 & 9.15 \\
\hline Log(age at first birth - 14) & 2.22 & 2.16 & 2.23 \\
\hline Age since first birth & 8.69 & 6.38 & 3.86 \\
\hline Age since first birth / age at first birth & 1.00 & 0.82 & 0.47 \\
\hline Currently in school & 1.86 & 1.40 & 3.14 \\
\hline
\end{tabular}

Source: Waves 1-4 of the Turning Points of the Life Course pane/ survey (2001, 2004, 2008 and 2012), Hungarian Demographic Research Institute. 
Panel B: Dataset of persons

\begin{tabular}{lccc} 
Variables & $\begin{array}{c}\text { Cohort } \\
1951-1960 \\
(\mathrm{~N}=553)\end{array}$ & $\begin{array}{c}\text { Cohort } \\
1961-1970 \\
(\mathrm{~N}=528)\end{array}$ & $\begin{array}{c}\text { Cohort } \\
1971-1980 \\
(\mathrm{~N}=576)\end{array}$ \\
\hline $\begin{array}{l}\text { Second conceptions } \\
\text { Partnership type }\end{array}$ & 0.47 & 0.56 & 0.20 \\
hypogamous & 22.43 & 22.76 & 24.09 \\
homogamous & 50.22 & 56.15 & 58.02 \\
hypergamous & 27.33 & 21.07 & 17.88 \\
Education & & & \\
vocational & 34.38 & 39.30 & 36.48 \\
secondary & 49.37 & 40.85 & 38.44 \\
tertiary & 16.23 & 19.83 & 25.07 \\
Educational pairing & & & \\
She vocational - He lower & 3.79 & 1.29 & 2.41 \\
She vocational - He vocational & 19.43 & 26.29 & 24.13 \\
She vocational - He higher & 11.15 & 11.71 & 9.93 \\
She secondary - He lower & 14.50 & 15.17 & 13.79 \\
She secondary - He secondary & 18.69 & 16.32 & 16.70 \\
She secondary - He higher & 16.17 & 9.35 & 7.94 \\
She tertiary - He lower & 4.13 & 6.30 & 7.88 \\
She tertiary - He tertiary & 12.09 & 13.53 & 17.18 \\
Age at first birth - 15 & 8.51 & 8.66 & 9.78
\end{tabular}

Note: with the exception of age variables, figures are percentages.

Source: Waves 1-4 of the Turning Points of the Life Course panel survey (2001, 2004, 2008 and 2012), Hungarian Demographic Research Institute. 